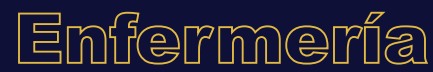

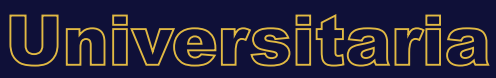

\section{Intervenciones psicológicas en cuidadores primarios de pacientes con trasplante de células hematopoyéticas: Revisión descriptiva}

Psychological interventions on primary care healthcare providers of patients with hematopoietic cells transplantation: Descriptive revision

\section{Intervenções psicológicas em cuidadores primários de pacientes com transplante de células hematopoiéticas: Revisão descritiva}

L. Brenes-Mesa ${ }^{a 1,2}$, L.M. Valero-Saldaña ${ }^{\text {b2 }}$, B.L. Acosta-Maldonado ${ }^{\mathrm{c} 2}$, M.R. Rodríguez-Aguilar ${ }^{\mathrm{d} 2,3}$, J.L. Aguilar-Ponce ${ }^{\mathrm{e}}$, L. Rivera-Fong ${ }^{\mathrm{f}, 5 *}$

ORCID:

a $0000-0001-9789-786 \mathrm{X}$

d $\underline{0000-0002-2491-5040}$

b $0000-0001-7225-3486$

e $0000-0002-9960-8547$

c0000-0003-4692-0710

${ }^{\mathrm{f}} 0000-0003-4155-9954$

${ }^{1}$ Universidad Intercontinental, Facultad de Psicología, Ciudad de México, México

${ }^{2}$ Instituto Nacional de Cancerología, Servicio de Hematología, Unidad de Trasplante de Médula Ósea, Ciudad de México, México

3 Universidad Latina, Campus Sur, Ciudad de México, México

4 Instituto Nacional de Cancerología, Ciudad de México, México

${ }^{5}$ Universidad Nacional Autónoma de México, Facultad de Psicología, Ciudad de México, México

Recibido: 03 octubre 2019

Aceptado: 06 diciembre 2019

*Autora para correspondencia. Correo electrónico: lmeylenf@hotmail.com

https://doi.org/10.22201/eneo.23958421e.2020.2.742

1665-7063/@ 2020 Universidad Nacional Autónoma de México, Escuela Nacional de Enfermería y Obstetricia. Este es un

artículo Open Access bajo la licencia CC BY-NC-ND (http://creativecommons.org/licenses/by-nc-nd/4.o/). 


\section{RESUMEN}

Introducción: El ser cuidador primario informal de un paciente con indicación médica de trasplante de células progenitoras hematopoyéticas puede tener consecuencias negativas en su salud mental y calidad de vida.

Objetivo: Describir las intervenciones psicológicas disponibles para el cuidador primario de pacientes sometidos a trasplante de células hematopoyéticas.

Metodología: Se realizó una búsqueda sistematizada de los últimos 10 años con los términos MeSH: psychotherapy AND caregive AND stem cell transplantation en las principales bases de datos médicas y de psicología, para su análisis se empleó la estrategia: Problema, Intervención, Comparación y Outcomes (PICO).

Resultados: Se identificaron 122 artículos, de ellos diez cumplieron los criterios de inclusión. Las intervenciones provenían de profesionales de enfermería o trabajo social; el 50\% incluyó diadas (paciente y cuidador primario), mostraron una tendencia de duración corta, enfocada al periodo posterior al trasplante. Se basan en el entrenamiento en solución de problemas, manejo de estrés, atención plena y expresión emocional. Las intervenciones lograron la disminución de la depresión, ansiedad y estrés en el cuidador; pero no alcanzaron permanencia en la significancia estadística de dichos restablecimientos.

Discusión: De acuerdo con lo observado en las publicaciones y por su impacto positivo en la salud mental, se recomienda la implementación de intervenciones psicológicas en cuidadores de pacientes con trasplante de células progenitoras hematopoyéticas.

Conclusión: El apoyo psicológico brindado al cuidador generalmente es de profesionales de la salud que no pertenecen al área de la psicología, con resultados clínicos favorables en las etapas más críticas de su estado mental.

Palabras clave: Cuidadores; trasplante de células progenitoras hematopoyéticas; salud mental; intervenciones psicológicas; psicoterapia; México.

\section{ABSTRACT}

Introduction: Being an informal primary healthcare provider of a patient who undergoes hematopoietic progeny cells transplantation can have adverse consequences on mental health and the quality of life.

Objective: To describe the available psychological interventions for the primary healthcare provider of patients undergoing hematopoietic cells transplantations.

Methodology: A systematized search of the last 10 years using the MeSH terms psychotherapy AND caregiver AND stem cell transplantation was conducted on the main medical and psychological databases. The analysis strategy followed the PICO scheme (Problem, Intervention, Comparison, Outcomes).

Results: 122 articles were identified, and 10 of them fulfilled the inclusion criteria. The interventions were related to nursing or social work professionals. 50\% described patienthealthcare provider dyads with short interventions focused on the post-transplantation period.

Discussion: According to what has been observed in the publications and due to its positive impact on mental health, the implementation of psychological interventions is recommended in caregivers of patients who underwent hematopoietic stem cell transplantation. 
Conclusion: The psychological support provided to the caregiver comes mainly from health professionals who do not belong to the area of psychology, with favorable clinical results in the most critical periods for their mental state.

Keywords: Caregivers; hematopoietic progenitor cell transplantation; mental health; psychological interventions; psychotherapy; Mexico.

\section{RESUMO}

Introdução: Ser cuidador primário informal de um paciente sometido a transplante de células progenitoras hematopoiéticas pode ter consequências negativas na saúde mental e na qualidade de vida.

Objetivo: Descrever as intervenções psicológicas disponíveis para o cuidador primário de pacientes sometidos a transplante de células hematopoiéticas.

Metodologia: Realizou-se uma busca sistematizada dos últimos 10 anos com os termos MeSH: psychotherapy AND caregive AND stem cell transplantation nas principais bases de dados médicas e de psicologia, para sua análise realizou-se a estratégia: Problema, Intervenção, Comparação e Outcomes (PICO).

Resultados: Identificaram-se 122 artigos, dos quais, dez cumpriram os critérios de inclusão. As intervenções provinham de profissionais em enfermagem ou trabalho social; o 50\% incluiu díades (paciente e cuidador primário), mostraram uma tendência de duração curta,focalizada no período posterior ao transplante. Baseiam-se no treinamento em solução de problemas, manejo de estresse, atenção plena e expressão emocional. As intervenções conseguiram melhoras clínicas na diminuição da depressão, ansiedade e estresse no cuidador; mas não alcançaram permanência na significância estatística destes restabelecimentos.

Discussão: Conforme o observado nas publicações e por seu impacto positivo na saúde mental, recomenda-se a implementação de intervenções psicológicas em cuidadores de pacientes para quem se indicou transplante de células progenitoras hematopoiéticas.

Conclusão: $\mathrm{O}$ apoio psicológico oferecido ao cuidador vem de principalmente profissionais da saúde que não pertencem à área da psicologia, com resultados clínicos favoráveis nos períodos mais críticos para seu estado mental.

Palavras chave: Cuidadores; transplante de células progenitoras hematopoiéticas; saúde mental; intervenções psicológicas; psicoterapia; México.

\section{INTRODUCCIÓN}

En las últimas tres décadas, el Trasplante de Células Progenitoras Hematopoyéticas (TCPH) se ha empleado con mayor frecuencia como parte del tratamiento de consolidación de diversas enfermedades hematológicas. De acuerdo con los registros oficiales, en Estados Unidos se realizaron 22863 trasplantes durante el año $2017^{1}$. A nivel mundial se realizan aproximadamente 50 ooo TCPH cada año en más de 70 países ${ }^{2,3}$.

El TCPH tiene por objetivo restaurar la médula del paciente mediante la administración de altas dosis de quimioterapia, seguido de la infusión de células progenitoras hematopoyéticas provenientes del mismo paciente o de un donador ${ }^{4.5}$. Durante el tiempo en que la nueva médula se reconstituye, los pacientes se encuentran expuestos a riesgos como infecciones y complicaciones que pueden conferir alta mortalidad, por lo que es indispensable un monitoreo médico constante y, en la mayoría de los casos, una hospitalización de aproximadamente 30 días ${ }^{6,7}$. 
Debido al alto riesgo relacionado con la patología principal, los tratamientos previos y el propio TCPH; el paciente requiere medidas de cuidado y seguimiento que incluyen constantes análisis, revisiones médicas, estrictas rutinas de higiene, además de una adecuada alimentación. Estas demandas, aunadas a los altos costos del trasplante ${ }^{8-10}$, exponen a los pacientes y familiares a estresores continuos que propician desgaste físico y emocional, situación donde es oportuna la intervención multidisciplinaria de profesionales de la salud para afrontarlo adecuadamente ${ }^{9-11}$.

Entre los requerimientos para someterse a un trasplante, el contar con un Cuidador Primario Informal (CPI) que acompañe al paciente es vital. El cuidador cumple con múltiples funciones que incluyen: contribuir al equilibrio y estabilidad emocional del paciente; favorecer la adherencia al tratamiento; auxiliar en las medidas de higiene, nutrición, ocio, así como descanso; realizar trámites hospitalarios; proveer y ministrar medicamentos; asistencia en actividades relacionadas con la rehabilitación con el fortalecer la adaptación a la cotidianidad ${ }^{6,12-17}$. Todas estas acciones son parte de los objetivos que se relacionan con el índice elevado de supervivencia junto con la calidad de vida, durante y después del trasplante ${ }^{18,19}$.

El papel del CPI en este proceso es tan relevante que su función y la relación que este tiene con el paciente puede repercutir en prolongar la duración de la estancia hospitalaria y el número de reingresos posteriores al $\mathrm{TCPH}^{20}$, de igual forma existe evidencia de que la presencia de un cuidador combinado a una red de apoyo social favorece la supervivencia integral de los pacientes ${ }^{21,22}$ y la adherencia a la terapia farmacológica tras el trasplante ${ }^{23}$.

Por lo visto, las demandas a las que se enfrenta el CPI de un paciente sometido a TCPH son diversas ya que requieren de capacitación especializada. Se sabe que esta tarea la realizan, por lo común, familiares como padres, hermanos, hijos o pareja ${ }^{24}$; con recursos y conocimientos deficientes para desempeñarse con éxito9,25. El estrés generado por las altas demandas, las preocupaciones por la salud de su familiar, además de las situaciones personales que enfrentan los cuidadores en su vida diaria, se asocian con el detrimento en su estado físico y emocional ${ }^{10,24,26}$, así como en la calidad de sus relaciones personales ${ }^{27-28}$.

Estudios sobre comportamientos saludables en CPI de pacientes hospitalizados para TPCH han documentado que hasta dos terceras partes tiene sobrepeso u obesidad y el 60.3\% padece alguna otra enfermedad crónica. En cuanto a la sintomatología psicológica, se ha descrito que el $65.8 \%$ reporta baja calidad de sueño y $7.8 \%$ sufren niveles de malestar emocional clínicamente significativos ${ }^{15}$. Al comparar la sintomatología psicológica de los CPI con parámetros para población general, se encontró que el $45 \%$ presentaban puntajes más altos en depresión, $67 \%$ tienen alteraciones en el estado de ánimo, 68\% reportan niveles clínicos de ansiedad, el 65\% muestra estrés percibido alto y el $100 \%$ tiene peor calidad de sueño que sus pares que no están a cargo de un paciente con enfermedad crónica ${ }^{29}$.

De esta forma, los CPI presentan alteraciones de ansiedad, depresión y estrés más altas que la población general. Por otro lado, entre las consecuencias a nivel fisiológico se ha identificado que cuando el paciente comienza su tratamiento médico, los cuidadores muestran elevación de parámetros de cortisol y epinefrina en suero; dichos niveles tienden a disminuir con el paso del tiempo, lo que podría indicar que los CPI generan cierta adaptación fisiológica ante los estresores crónicos ${ }^{12}$.

El impacto generado en los CPI se manifiesta a largo plazo; se observó que las parejas de pacientes sometidos a TCPH tienen una probabilidad 3.5 mayor de desarrollar un episodio depresivo en comparación con la población general, incluso si han transcurrido años desde el procedimiento. Aledaño a esto, la probabilidad para los cuidadores de recibir tratamiento psicológico es menor; 
presentan aumento en la percepción de soledad, el apoyo social para ellos es limitado en contraste con el de los receptores ${ }^{30}$.

El desgaste llega a tener niveles de sobrecarga comparables con los presentados por cuidadores de pacientes con cáncer avanzado, así como mayor estrés que los CPI de enfermos de Alzheimer ${ }^{31}$. Este deterioro se agrava cuando el cuidador deja de lado sus necesidades básicas ${ }^{15,25}$.

En contexto, los compromisos que adquiere un cuidador son múltiples; con tendencia a cumplir actividades propias del personal de enfermería ${ }^{50}$, principalmente cuando el paciente de TCPH egresa del hospital y debe continuar con los cuidados en casa. De ahí que, el desgaste o alteraciones en la salud mental como física del CPI afectan la calidad de los cuidados que brinda; por ende, en el receptor, se presentan aumento de síntomas y disminución del apego al tratamiento. Este escenario genera un incremento en las demandas de atención de salud, además de impactar negativamente en la relación médico-paciente. En los casos graves, podrían presentarse complicaciones en el enfermo que entorpezcan su evolución.

Ante estas alteraciones y la importancia del CPI para el éxito del trasplante, diversos autores destacan la necesidad de llevar a cabo intervenciones psicológicas oportunas en esta población ${ }^{15,16,24,25,32-36}$. Es esencial integrar un programa preventivo enfocado en el autocuidado y el desarrollo de habilidades para solución de problemas, así como, entrenamiento en cuidados específicos del receptor de TCPH9, $95,26,37$.

Se busca que estas intervenciones favorezcan que los CPI desarrollen habilidades y pongan en práctica estrategias para hacerse cargo de manera óptima de los cuidados del paciente; situación que podría reducir la carga de trabajo y atención requerida por parte del personal de salud, un CPI con capacitación adecuada puede favorecer la disminución de los riesgos y complicaciones médicas en el receptor.

No obstante, las recomendaciones y la claridad de los posibles beneficios existen pocas intervenciones psicológicas diseñadas para tal población ${ }^{38,39}$, por lo que la evidencia sobre la efectividad de las mismas es limitada y poco difundida. Ante tal panorama no son precisos los datos sobre cómo se ha evaluado el estado previo psicológico de los cuidadores, cuál es el momento de inicio de las intervenciones, qué componentes o variables incluyeron, además de cómo estimaron su efectividad. Con el propósito de dar a conocer las alternativas de intervención psicológica para CPI, sensibilizar al personal de salud sobre su uso y orientar la toma de decisiones hacia su implementación oportuna; el objetivo de este estudio fue describir las intervenciones psicológicas para CPI de pacientes adultos y pediátricos sometidos a TCPH reportadas en literatura.

\section{MÉTODO}

Estudio de revisión descriptiva de literatura, se realizó una búsqueda sistemática en cuatro bases de datos para medicina y psicología (PubMed, Scopus, Redalyc y EBSCOhost). Estas plataformas se seleccionaron por su mayor concentración de artículos médicos y psicológicos de habla inglesa y en español. Se usaron los términos MeSH: stem cell transplantation AND caregivers AND psychotherapy.

Como criterios de inclusión se consideraron artículos publicados entre el 2010-2020, en idioma español o inglés, que incluyeran intervenciones aplicadas a CPI de pacientes adultos o pediátricos sometidos a TCPH. Los artículos identificados se analizaron con la estrategia: Población, Intervención, Control y Outcomes (PICO), con el fin de conocer los detalles de la intervención, así como resultados obtenidos. Adicionalmente, se evaluaron aspectos del diseño y análisis estadísticos empleados en cada intervención para determinar el nivel de evidencia científica; la categorización se consideró a partir de los criterios propuestos por el equipo de trabajo canadiense: Canadian Task Force on 
Preventive Health Care (CTFPHC), sobre la atención médica preventiva, los cuales se basan en las fuentes de validez interna consideradas en el estudio ${ }^{40}$.

\section{RESULTADOS}

La búsqueda arrojó 122 artículos originales; de los cuales 112 fueron descartados por una o más de las siguientes razones: a) describir únicamente el protocolo de intervención, sin datos sobre su implementación; b) tratarse de intervenciones no psicológicas; c) no corresponder a intervenciones o d) no estar enfocados en cuidadores de TCPH. Tras dicha depuración, se incluyeron diez artículos en la revisión final, de los cuales un estudio incluyó CPI de pacientes sometidos a TCPH y trasplante de órganos sólidos.

El 90\% de los artículos fueron realizados en Estados Unidos; por seis grupos de investigación diferentes. El más antiguo fue publicado en el 2010, mientras los estudios más recientes datan del año 2020.

De las intervenciones documentadas en los artículos, destaca que dos de ellos reportan hallazgos en diferentes niveles de profundización sobre la misma intervención ${ }^{41,42}$; de manera que hay nueve intervenciones originales incluidas en el estudio. Otra investigación del mismo equipo se realizó posterior al primer ensayo clínico, a forma de réplica, con ligeras modificaciones. De las nueve intervenciones, tres se enfocaron en la diada paciente-cuidador, mientras las otras siete se centraron exclusivamente en el cuidador. De estas últimas, sólo una evaluó los efectos en el paciente.

Las intervenciones empleadas en todos los estudios fueron de corta duración con un rango de tres a diez sesiones, de máximo 75 minutos cada una; en relación a las técnicas utilizadas en dos proyectos de investigación se implementaron intervenciones basadas en solución de problemas 43.44 , en una se empleó un entrenamiento en resiliencia basado en atención plena ${ }^{45}$, en dos de ellas utilizaron una intervención para manejo de estrés ${ }^{41,42}$, la terapia de apoyo fue aplicada en un estudio, la terapia centrada en estrategias de afrontamiento se efectuó en una investigación, la intervención basada en la teoría del procesamiento cognitivo-social de ajuste a eventos traumáticos fue integrada en un estudio y, finalmente, la terapia de expresión emocional se empleó en una publicación ${ }^{46}$. Solo en dos investigaciones estuvieron enfocados a CPI pediátricos con intervenciones de tres a cinco sesiones.

En la tabla 1 se puede observar que, en todos los estudios, las evaluaciones de las intervenciones fueron de mejoría; nueve de ellas tuvieron significancia estadística ${ }^{41,42,44,45}$. De las publicaciones que

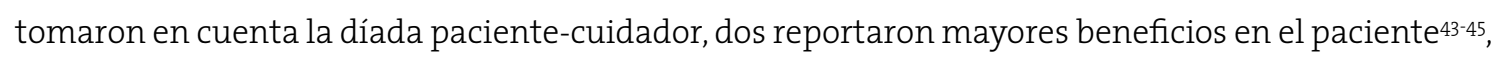
mientras que uno mostró beneficios significativos para el cuidador ${ }^{43}$.

De las siete intervenciones enfocadas únicamente en el cuidador, la de expresión emocional fue percibida por los participantes como significativa y de ayuda para entender sus sentimientos, aunque no se implementaron instrumentos para medir afectaciones emocionales de forma objetiva ${ }^{47}$. En cuanto a lo realizado por Laudenslager et al., el estudio inicial observó disminución en los niveles de estrés, ansiedad y depresión ${ }^{41}$; sin embargo, no hubo cambios en las medidas de respuesta de cortisol; dentro del mismo grupo la profundización de los hallazgos mostró diferencia significativa en la respuesta inflamatoria. Otra publicación en 2019 por los mismos autores, mostró que la eficacia de la intervención se mantiene al agregar herramientas tecnológicas como atención remota. Este segundo ensayo clínico reiteró la disminución en el distrés de los cuidadores, aunque no hubo cambios en la calidad de vida. En general, las intervenciones con menor número de sesiones, tres o cuatro, no se advirtieron mejoras. 


\begin{tabular}{|c|c|c|c|c|}
\hline & $\mathbf{P}$ & I & C & $\mathbf{0}$ \\
\hline Cita & Participantes & Intervención & Grupo control & Resultado \\
\hline 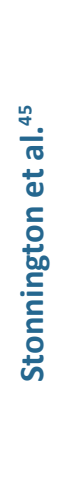 & $\begin{array}{l}18 \text { CPI (F: } 14 \text { y M: 4). Edad } \\
\text { promedio } 60 \text { años. } \\
\text { Evaluaciones pre } \\
\text { intervención y dos } \\
\text { seguimientos. Utilizaron: } \\
\text { Escala de Estrés Percibido, } \\
\text { Escala de Resiliencia } \\
\text { Connor-Davidson, el } \\
\text { PHQ-9, el GAD-7, la SF- } \\
36, \text { la PANAS, Escala de } \\
\text { Consciencia de Atención } \\
\text { Plena y una medición } \\
\text { subjetiva de calidad del } \\
\text { sueño. }\end{array}$ & $\begin{array}{l}\text { Intervención grupal (15 a } 20 \\
\text { participantes por grupo). } \\
\text { Seis sesiones semanales de } \\
\text { Entrenamiento de Resiliencia } \\
\text { basado en Mindfulness (MBRT). } \\
\text { La intervención incluyó psico- } \\
\text { educación, entrenamiento } \\
\text { atencional y de conciencia sobre } \\
\text { las respuestas automáticas. }\end{array}$ & $\begin{array}{l}\text { No se incluyó } \\
\text { grupo control. }\end{array}$ & $\begin{array}{l}\text { Con respecto a la percepción } \\
\text { de estrés, progresivamente } \\
\text { los CPI mostraron mejoría } \\
\text { significativa ( } x=15.7 \text { vs } x=12.5 \\
\text { vs } x=10.1 ; p=.0384) \text {. } \\
\text { En ansiedad y atención plena } \\
\text { se observaron signos positivos } \\
\text { de potencial mejora. }\end{array}$ \\
\hline 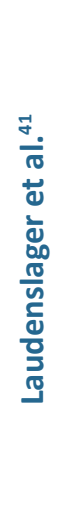 & $\begin{array}{l}148 \mathrm{CPI} \text { de pacientes } \\
\text { sometidos a TCPH } \\
\text { alogénico. } \\
\text { Tres mediciones: una } \\
\text { preTCPH y seguimientos } \\
\text { a los meses uno y tres } \\
\text { posTCPH. } \\
\text { La evaluación incluyó } \\
\text { el PSS, CESD, STAI, CRA, } \\
\text { POMS-TMD, PSQI, SF-36 y } \\
\text { el IES. }\end{array}$ & $\begin{array}{l}\text { Ocho sesiones individuales } \\
\text { iniciadas en el día } 16+10 \text { posTCPH. } \\
\text { Se basaron en un programa PEPRR } \\
\text { basado en el Modelo Transaccional } \\
\text { de Estrés y Afrontamiento. } \\
\text { El programa incluyó bio- } \\
\text { retroalimentación, análisis de } \\
\text { los factores asociados al estrés, } \\
\text { entrenamiento en habilidades } \\
\text { de afrontamiento, autocontrol, } \\
\text { comunicación, adaptación y apoyo } \\
\text { social. } \\
\text { Se agregó un libro con los } \\
\text { temas de las sesiones y tareas } \\
\text { recomendadas. }\end{array}$ & $\begin{array}{l}74 \text { participantes } \\
\text { tuvieron acceso } \\
\text { a los servicios de } \\
\text { apoyo psico- } \\
\text { social de la clínica } \\
\text { (Grupo TAU). } \\
\text { Los grupos fueron } \\
\text { aleatorizados. }\end{array}$ & $\begin{array}{l}\text { Niveles de estrés percibido } \\
\text { significativamente más bajos } \\
\text { en el grupo PERRR ( } t=2.09 ; \\
p=0.039 \text { ) que el TAU a tres } \\
\text { meses. } \\
\text { Niveles de ansiedad y } \\
\text { depresión más bajos en el } \\
\text { grupo PERRR que en el TAU. } \\
\text { Sin diferencias entre grupos en } \\
\text { cortisol ni otros marcadores } \\
\text { biológicos. }\end{array}$ \\
\hline 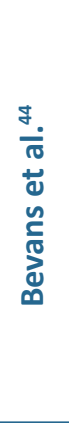 & $\begin{array}{l}72 \mathrm{CPI} \text { de pacientes } \\
\text { sometidos a TCPH. } \\
\text { Tres evaluaciones: } \\
\text { (a) pre-TCPH, (b) al } \\
\text { alta hospitalaria (pre- } \\
\text { intervención) y (c) } \\
\text { seguimiento a seis } \\
\text { semanas. } \\
\text { Se aplicaron el CASE-t, el } \\
\text { BSI, el HPLP-II, el PSQI, el } \\
\text { MFSI-SF y una Escala de } \\
\text { Mutualidad. }\end{array}$ & $\begin{array}{l}\text { Intervención de tres sesiones } \\
\text { dirigidas por trabajadores } \\
\text { sociales y personal de } \\
\text { enfermería; realizadas durante la } \\
\text { hospitalización del paciente. } \\
\text { Con base en la Terapia de } \\
\text { Solución de Problemas Sociales } \\
\text { emplearon el modelo: Creatividad, } \\
\text { Optimismo, Planeación e } \\
\text { Información Especializada (COPE). }\end{array}$ & $\begin{array}{l}\text { No se incluyó } \\
\text { grupo control. }\end{array}$ & $\begin{array}{l}\text { No se encontraron diferencias } \\
\text { estadísticamente significativas } \\
\text { entre grupos. } \\
\text { Los CPI que terminaron } \\
\text { el estudio y se mostraron } \\
\text { participativos identificaron } \\
\text { mejoría en autoeficacia } \\
\text { (x=149.7 vs } x=154, p=.028 \text { ). }\end{array}$ \\
\hline 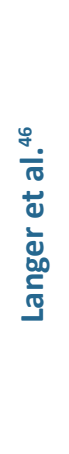 & $\begin{array}{l}29 \text { CPI casados o en } \\
\text { concubinato con el } \\
\text { paciente. }\end{array}$ & $\begin{array}{l}\text { Intervención de tres sesiones de } 10 \\
\text { minutos de expresión emocional } \\
\text { respecto a sus pensamientos y } \\
\text { sentimientos sobre el TCPH. } \\
\text { Las sesiones se analizaron con el } \\
\text { Lexical Inquiry and Word Count } \\
\text { Program; se midió la respuesta } \\
\text { electrodérmica y los afectos } \\
\text { positivos y negativos. }\end{array}$ & $\begin{array}{l}\text { Dos sesiones en } \\
\text { las que hablaron } \\
\text { de planes para la } \\
\text { siguiente semana } \\
\text { como también de } \\
\text { aspectos positivos } \\
\text { de su vida. }\end{array}$ & $\begin{array}{l}\text { Hubo efectos en PANAS por } \\
\text { grupo ( } p=.03 \text { ) y sesión ( } p=.002) \text {. } \\
\text { La conductancia mostró } \\
\text { efectos principales por tiempo } \\
\text { ( } p<.0001) \text {, sesión ( } p=.005) \text { y } \\
\text { efectos por interacción grupo X } \\
\text { sesión ( } p=.02 \text { ). } \\
\text { Los ejercicios del grupo de } \\
\text { intervención se percibieron } \\
\text { más útiles ( } p=.005 \text { ), } \\
\text { significativos ( } p=.04 \text { ) y } \\
\text { reveladores de sus emociones } \\
\text { ( } p=.0001 \text { ) que los del control. }\end{array}$ \\
\hline
\end{tabular}




\begin{tabular}{|c|c|c|c|c|}
\hline 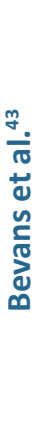 & $\begin{array}{l}10 \text { díadas de paciente de } \\
\text { TCPH alogénico - CPI. } \\
\text { Dos evaluaciones en línea } \\
\text { base (pre y post al UCE), } \\
\text { dos durante la intervención } \\
\text { PSE y dos después de la } \\
\text { última sesión. } \\
\text { La evaluación incluyó el } \\
\text { BSI, el SPSI-R, el FACES IV, la } \\
\text { SDS y una entrevista semi- } \\
\text { estructurada. }\end{array}$ & $\begin{array}{l}\text { Programa PSE de cuatro sesiones } \\
\text { dirigidas por un especialista en } \\
\text { enfermería o trabajo social. Se } \\
\text { adaptó del modelo de cuidador } \\
\text { familiar preparado (COPE). } \\
\text { Se revisó el modelo de solución } \\
\text { de problemas y el modelo COPE. } \\
\text { Además de un programa educativo } \\
\text { sobre el TCPH y el alta (UCE). }\end{array}$ & $\begin{array}{l}\text { No se incluyó } \\
\text { grupo control. }\end{array}$ & $\begin{array}{l}\text { El tamaño del efecto de las } \\
\text { estrategias en solución de } \\
\text { problemas fue mayor para los } \\
\text { pacientes ( } E S=.324, M=16.48 \\
\pm 1.49 \text { vs } 17.02 \pm 2.4 \text { ) que } \\
\text { para los cuidadores ( } E S=.067 \text {, } \\
M=14.18 \pm 2.7 \text { vs } 14.09 \pm 2.6) \text {. } \\
\text { El tamaño del efecto en } B S I \\
\text { en } C P I \text { fue pequeño }(E S=.128 \text {, } \\
M=5.1 \pm 3.8 \text { vs } 4.7 \pm 3.3) \\
\text { con resultados ligeramente } \\
\text { menores en el seguimiento. }\end{array}$ \\
\hline 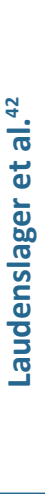 & $\begin{array}{l}45 \text { CPI de pacientes } \\
\text { sometidos a TCPH } \\
\text { alogénico. } \\
\text { En } 5 \text { momentos se } \\
\text { tomaron muestras de } \\
\text { sangre de los CPI (línea } \\
\text { base y seguimientos [1, 3, } \\
6 \text { y } 12 \text { meses posTCPH]) } \\
\text { para realizar un perfil de } \\
\text { expresión genética. } \\
\text { Además se usó el PSS, el } \\
\text { CESD y el STAI. }\end{array}$ & $\begin{array}{l}23 \text { participantes recibieron un } \\
\text { programa de manejo de estrés y } \\
\text { psico-educación (PEPRR) de ocho } \\
\text { sesiones dirigidas por un maestro } \\
\text { en trabajo social. } \\
\text { Incluyó aspectos sobre el manejo e } \\
\text { impacto del estrés, entrenamiento } \\
\text { en habilidades de afrontamiento y } \\
\text { conductas de salud, estrategias de } \\
\text { comunicación, cambio de roles y } \\
\text { uso efectivo del apoyo social. }\end{array}$ & $\begin{array}{l}22 \mathrm{CPI} \text { asignados } \\
\text { a TAU que } \\
\text { consistía en } \\
\text { acceso a los } \\
\text { servicios de } \\
\text { apoyo psico-social } \\
\text { en la clínica. }\end{array}$ & $\begin{array}{l}\text { CPI del grupo PEPRR tuvieron } \\
\text { menores niveles en estrés } \\
\text { percibido ( } 18 \pm 2 \text { vs } 22 \pm 3 \text { ) } \\
\text { depresión }(10 \pm 2 \text { vs } 15 \pm 3 \text { ) y } \\
\text { ansiedad ( } 34 \pm 2 \text { vs } 38 \pm 4 \text { ) en } \\
\text { comparación con el grupo TAU } \\
\text { a } 3 \text { meses. Estas diferencias no } \\
\text { fueron significativas. } \\
57 \text { genes mostraron }>1.5 \\
\text { veces mejor up-regulation a } \\
\text { través del tiempo en el grupo } \\
\text { PEPRR que en TAU y } 47 \text { genes } \\
\text { mostraron >1.5 veces mejor } \\
\text { down-regulation. }\end{array}$ \\
\hline 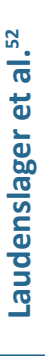 & $\begin{array}{l}155 \text { diadas de paciente } \\
\text { sometidos a TCPH } \\
\text { alogénico - CPI. } \\
\text { Se aleatorizaron y } \\
\text { evaluaron en la línea base y } \\
\text { a los meses } 1.5,3 \text { y } 6 \text { meses } \\
\text { después del TCPH. } \\
\text { Los CPI respondieron el } \\
\text { CES-D, STAI-S, PSS, CG- } \\
\text { distress y CRA. }\end{array}$ & $\begin{array}{l}75 \text { CPI recibieron un programa } \\
\text { PEPRR de } 8 \text { sesiones PEPRR y } 2 \\
\text { sesiones opcionales al final. } \\
\text { La atención fue mediante celular } \\
\text { apoyado con un libro de trabajo } \\
\text { sobre las sesiones. Además de } \\
\text { recibir un dispositivo de bio- } \\
\text { feedback para los ejercicios de } \\
\text { relajación. }\end{array}$ & $\begin{array}{l}80 \text { CPI se } \\
\text { asignaron de } \\
\text { forma aleatoria } \\
\text { a TAU que sólo } \\
\text { recibieron el libro } \\
\text { de trabajo. }\end{array}$ & $\begin{array}{l}\text { Los CPI del grupo PEPRR } \\
\text { tuvieron disminuciones } \\
\text { significativamente mayores en } \\
\text { distrés en comparación con el } \\
\text { grupo TAU }(\mathrm{M}=-0.20 ; 95 \% \mathrm{Cl} \text { vs } \\
\mathrm{M}=0.14 ; 95 \% \mathrm{Cl}) \text {. }\end{array}$ \\
\hline 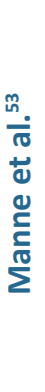 & $\begin{array}{l}218 \mathrm{CPI} \text { de pacientes } \\
\text { pediátricos (< } 19 \text { años). } \\
\text { Cuatro momentos } \\
\text { de evaluación: pre- } \\
\text { intervención, } 1,6 \text { y } 12 \\
\text { meses post-intervención. } \\
\text { Se empleó el BDI, el BAI, la } \\
\text { IES y la escala de bienestar } \\
\text { del MHI. }\end{array}$ & $\begin{array}{l}110 \text { CPI participaron en un } \\
\text { programa de } 5 \text { sesiones basado } \\
\text { en la teoría de procesamiento } \\
\text { cognitivo-social de ajuste a } \\
\text { eventos traumáticos (P-SCIP). } \\
\text { Se incluyó manejo del estrés y } \\
\text { preocupaciones sobre su } \\
\text { hijo, la forma de lidiar con } \\
\text { preocupaciones solucionables y } \\
\text { problemas inmutables sobre TCPH, } \\
\text { vida social y habilidades. }\end{array}$ & $\begin{array}{l}108 \mathrm{CPI} \text { fueron } \\
\text { asignados al } \\
\text { grupo BPC. } \\
\text { Este grupo } \\
\text { recibía material } \\
\text { informativo sobre } \\
\text { el cuidado y } \\
\text { manejo } \\
\text { emocional } \\
\text { de sus hijos. }\end{array}$ & $\begin{array}{l}\text { No se observó un efecto } \\
\text { principal por el tratamiento. } \\
\text { Se observó un efecto en la } \\
\text { interacción condición x tiempo } \\
\text { en ansiedad }(p<0.01) \text { y distrés } \\
\text { traumático }(p<0.05) \text {. }\end{array}$ \\
\hline 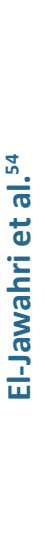 & $\begin{array}{l}92 \text { CPI de pacientes de } \\
\text { TCPH alogénico o autólogo. } \\
\text { Se aplicaron el CarGOQOL, } \\
\text { CRA, HADS, CASE-T y } \\
\text { MOCS. } \\
\text { Evaluación pre-intervención y } \\
\text { a los días }+30 \text { y }+60 \text { del } \\
\text { TCPH. }\end{array}$ & $\begin{array}{l}45 \text { CPI recibieron seis sesiones } \\
\text { sobre estrategias de afrontamiento } \\
\text { que integra educación sobre } \\
\text { TCPH con estrategias cognitivo- } \\
\text { conductuales BTM-CARE. } \\
\text { Se midieron índices de calidad } \\
\text { de vida, desgaste del cuidador, } \\
\text { síntomas de estado de ánimo y } \\
\text { ansiedad, confianza del cuidador } \\
\text { en el manejo del impacto del TCPH } \\
\text { y habilidades de afrontamiento } \\
\text { percibidas. }\end{array}$ & $\begin{array}{l}47 \mathrm{CPI} \text { asignados } \\
\text { aleatoriamente } \\
\text { que recibieron el } \\
\text { manejo usual del } \\
\text { hospital. }\end{array}$ & $\begin{array}{l}\text { Al día } 60 \text {, los CPI del grupo } \\
\text { BMT-CARE reportaron mejor } \\
\text { calidad de vida (media } \\
\text { ajustadas } 81.22 \text { vs } 70.96 ; d \\
\text { de Cohen=0.68; } p<0.001 \text { ); y } \\
\text { menores puntajes de } \\
\text { carga del cuidador (media } \\
\text { ajustadas } 45.95 \text { vs } 55.06 ; d \\
\text { de Cohen=0.73; } p<0.001 \text { ), de } \\
\text { síntomas de ansiedad (media } \\
\text { ajustadas } 3.62 \text { vs } 7.22 ; d \\
\text { de Cohen=0.96; } p<0.001 \text { ) y } \\
\text { depresión (media ajustadas } \\
2.85 \text { vs } 4.40 ; d \text { de Cohen=0.57; } \\
p<0.009 \text { ) en comparación con } \\
\text { el grupo control. }\end{array}$ \\
\hline
\end{tabular}




\begin{tabular}{|c|c|c|c|c|}
\hline 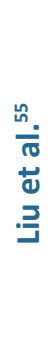 & $\begin{array}{l}45 \mathrm{CPI} \text { de pacientes } \\
\text { pediátricos de TCPH } \\
\text { alogénico. } \\
\text { Los participantes fueron } \\
\text { evaluados con el BAI, el } \\
\text { CES-D, el PSS y el CQOLC. } \\
\text { Evaluaciones previo al } \\
\text { TCPH, a los } 14 \text { días post- } \\
\text { TCPH y una semana antes } \\
\text { del alta hospitalaria. }\end{array}$ & $\begin{array}{l}22 \mathrm{CPI} \text { recibieron tres sesiones en } \\
\text { compartir experiencias pasadas, } \\
\text { promover el apoyo, información } \\
\text { médica importante y disminuir el } \\
\text { estrés. }\end{array}$ & $\begin{array}{l}\text { Se incluyeron } 23 \\
\mathrm{CPI} \text { que recibieron } \\
\text { información } \\
\text { por parte de } \\
\text { los médicos y } \\
\text { atención de una } \\
\text { enfermera para } \\
\text { resolver dudas. }\end{array}$ & $\begin{array}{l}\text { El grupo de intervención } \\
\text { presentó menor percepción } \\
\text { de estrés ( } p=0.03 \text { ) y mejor } \\
\text { calidad de vida ( } p=0.03 \text { ) en } \\
\text { comparación con el grupo } \\
\text { control a los cinco días. }\end{array}$ \\
\hline
\end{tabular}

TCPH: Trasplante de Células Progenitoras Hematopoyéticas; F: Femenino; M: Masculino; HPHQ-9: Cuestionario sobre la Salud del Paciente; GAD-7: Escala de Trastorno de Ansiedad Generalizada; SF-36: Cuestionario de Salud; PANAS: Escala de Afecto Positivo y Negativo; PEPRR: Programa de Psicoeducación, Respiración Rítmica y Relajación; TAU: Tratamiento Usual PSS: Escala de Estrés Percibido; CESD: Escala de Depresión del Centro de Estudios Epidemiológicos; STAI: Inventario de Ansiedad-Estado; CRA: Evaluación de la Reacción del Cuidador; POMS-TMD: Perfil de Estados de Ánimo; PSQI: Inventario de Calidad del Sueño de Pittsburgh; IES: Escala de Impacto de Eventos; CASE-t: Escala de Autoeficacia al Cáncer; BSI: Inventario Breve de Síntomas; HPLP-II: Evaluación de la Frecuencia de Conductas Saludables; MFSISF: Inventario de Síntomas Multidimensionales de la Fatiga - Versión Corta; LICW: Investigación sobre el léxico y conteo de palabras; PSE: Intervención de educación en solución de problemas; COPE: Creatividad, Optimismo, Planeación e Información Especializada; SPSI-R: Inventario de Solución de Problemas Sociales; FACES IV: Escala de Evaluación de la Cohesión y Adaptabilidad de la Familia; SDS: Escala de Síntomas de Malestar Emocional; FACT-BMT: Evaluación Funcional de la Terapia para cáncer- Trasplante de Médula Ósea; PSS: Escala de Estrés Percibido; CRA: Evaluación de la Reacción del Cuidador; BDI: Inventario de Depresión de Beck; BAI: Inventario de Ansiedad de Beck; IES: Escala de Impacto de Evento; MHI: Inventario de Salud Mental; P-SCIP: Programa de Intervención de Procesamiento Social Cognitivo para Padres. BPC: Mejores Prácticas de Cuidado Psicosocial; BTM-CARE: Intervención Psicosocial Multimodal; HADS: Escala de Depresión y Ansiedad Hospitalaria; MOCS: Medida de Estado Actual; CO_OLF: Índice de Calidad de Vida del Cuidador - Cáncer.

En la tabla 2 se describe el diseño de investigación empleado en cada una de las intervenciones, el análisis estadístico y los elementos que pudieron afectar la validez interna de los estudios. Entre las principales fuentes de invalidez observadas, resalta que tres de las publicaciones no contaron con grupo control, así como la mortalidad experimental presente en la mayoría de las investigaciones, ambas circunstancias redujeron de manera importante la validez. A pesar de ello, todos cuentan con un nivel de evidencia de por lo menos II que, al mostrar consistencia en los hallazgos con estudios similares, aportan solidez.

Tabla 2. Análisis metodológico de las intervenciones

\begin{tabular}{|c|c|c|c|c|c|}
\hline Cita & Diseño & Población & Análisis estadístico & $\begin{array}{l}\text { Fuente de invalidez } \\
\text { interna }\end{array}$ & $\begin{array}{l}\text { Nivel de } \\
\text { evidencia }\end{array}$ \\
\hline 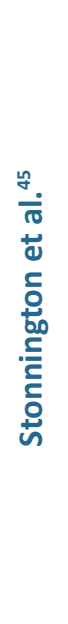 & $\begin{array}{l}\text { Pre-experimental } \\
\text { con medición } \\
\text { pre y post } \\
\text { intervención. }\end{array}$ & $\begin{array}{l}\text { Se excluyeron } \\
\text { sujetos con } \\
\text { abuso activo } \\
\text { de sustancias, } \\
\text { insuficiencia } \\
\text { cognitiva severa y } \\
\text { criterios de riesgo } \\
\text { de suicidio. }\end{array}$ & $\begin{array}{l}\text { Se empleó la corrección de } \\
\text { Bonferonni y control de la tasa de } \\
\text { hallazgo falso para controlar los } \\
\text { problemas derivados del uso de } \\
\text { múltiples pruebas. } \\
\text { Se consideró cambio clínicamente } \\
\text { significativo mediante el Índice de } \\
\text { Cambio Fiable (RCI) en las escalas } \\
\text { PCS, MCS, GAD-7 y PHQ-9. Se } \\
\text { empleó un método bimodal para } \\
\text { calcular el porcentaje de cambio } \\
\text { clínicamente significativo con un } \\
\text { intervalo de } 95 \% \text { de confianza. } \\
\text { Se emplearon análisis ANOVA para } \\
\text { comparar a los participantes que } \\
\text { completaron las evaluaciones y } \\
\text { prueba de Fisher para variables } \\
\text { categóricas. }\end{array}$ & $\begin{array}{l}\text { Falta de grupo control. } \\
19 \% \text { de los CP cumplieron } \\
\text { con menos de la mitad de las } \\
\text { sesiones. } \\
17 \% \text { de los CP no } \\
\text { completaron las evaluaciones } \\
\text { de línea base y seis semanas } \\
\text { post-intervención. } \\
\text { Las evaluaciones pre } \\
\text { intervención tuvieron una } \\
n \text { de } 13 \text { a } 18 \text {, las de seis } \\
\text { semanas } n \text { de } 11 \text { a } 15 \text { y la } \\
\text { evaluación a tres meses } n \text { de } \\
9 \text { a } 11 \text { sujetos. }\end{array}$ & II-3 \\
\hline
\end{tabular}




\begin{tabular}{|c|c|c|c|c|c|}
\hline 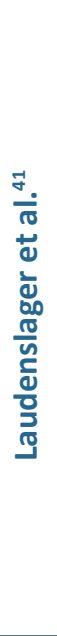 & $\begin{array}{l}\text { Estudio } \\
\text { experimental } \\
\text { pre y post prueba. } \\
\text { Estudio } \\
\text { aleatorizado } \\
\text { Confiabilidad } \\
>90 \% \text { del apego } \\
\text { del terapeuta al } \\
\text { manual. }\end{array}$ & $\begin{array}{l}\text { Se excluyeron CPI } \\
\text { con antecedentes } \\
\text { de trastorno } \\
\text { psiquiátrico en los } \\
\text { últimos } 18 \text { meses, } \\
\text { no relacionado } \\
\text { con el TCPH; } \\
\text { aquellos que } \\
\text { manifestaron una } \\
\text { condición médica } \\
\text { preexistente; o } \\
\text { bien consumo de } \\
\text { medicamentos } \\
\text { que pudieran } \\
\text { afectar los } \\
\text { biomarcadores. }\end{array}$ & $\begin{array}{l}\text { Las diferencias iniciales entre } \\
\text { variables sociodemográficas y } \\
\text { clave, fueron evaluadas mediante } \\
\text { X2; } t \text { de Student; } U \text { de Mann- } \\
\text { Whitney y Prueba de Fisher. } \\
\text { Los biomarcadores de cada grupo } \\
\text { se compararon mediante un } \\
\text { análisis de varianza (ANOVA) } \\
\text { Los resultados de los CPI se } \\
\text { analizaron mediante ANCOVA, } \\
\text { brindaron estimaciones grupales } \\
\text { en cada mes con efectos fijos } \\
\text { de intervención (PEPRR vs TAU), } \\
\text { tiempo (línea base, mes } 1 \text { y mes } \\
\text { 3), además de la interacción } \\
\text { mientras varía la edad del } \\
\text { cuidador. }\end{array}$ & $\begin{array}{l}84 \% \text { de los CPI no } \\
\text { fue constante en el } \\
\text { uso del dispositivo de } \\
\text { biorretroalimentación } \\
\text { durante la intervención; con } \\
\text { variabilidad en la adherencia. } \\
16 \% \text { de pacientes del TAU } \\
\text { y } 7 \% \text { del PEPRR acudieron } \\
\text { voluntariamente a por } \\
\text { lo menos una sesión del } \\
\text { programa de trasplantes que } \\
\text { se centra en el estrés del } \\
\text { cuidador, autocuidado, la } \\
\text { importancia de los recursos } \\
\text { de la comunidad y resolución } \\
\text { de problemas planteados por } \\
\text { los asistentes; sin medir el } \\
\text { efecto de esta intervención. }\end{array}$ & 1 \\
\hline 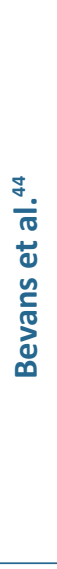 & $\begin{array}{l}\text { Diseño pre- } \\
\text { experimental de } \\
\text { pre y post prueba } \\
\text { con un solo } \\
\text { grupo. }\end{array}$ & $\begin{array}{l}\text { La mayoría de los } \\
\text { CPI que aceptaron } \\
\text { participar fueron } \\
\text { mujeres ( } 72 \%) \\
\text { caucásicas } \\
\text { ( } 77.8 \% \text { ) con una } \\
\text { edad promedio } \\
\text { de } 53 \text { años. }\end{array}$ & $\begin{array}{l}\text { Se evaluó y controló de manera } \\
\text { estadística la relación entre } \\
\text { la autoeficacia y el malestar } \\
\text { emocional con la duración del } \\
\text { cuidado, además del número de } \\
\text { sesiones a las que acudió el CPI. } \\
\text { Se empleó una } t \text { de Student } \\
\text { para muestras relacionadas para } \\
\text { comparar las mediciones pre y } \\
\text { post intervención, así como la } \\
d \text { de Cohen para determinar el } \\
\text { tamaño del efecto. } \\
\text { Se examinó el potencial } \\
\text { predictor de las variables } \\
\text { sociodemográficas mediante un } \\
\text { modelo de regresión por pasos. }\end{array}$ & $\begin{array}{l}\text { Muerte experimental del } \\
36.28 \% \text { de los CPI desde la } \\
\text { evaluación pre-intervención } \\
\text { hasta la evaluación post- } \\
\text { intervención. El } 94.4 \% \text { de los } \\
\mathrm{CPI} \text { acudió a la primera sesión, } \\
\text { el } 88.6 \% \text { a la segunda y el } \\
80 \% \text { a la tercera. } \\
\text { En el grupo de CPI que se } \\
\text { negaron a participar, se } \\
\text { observó que mostraban } \\
\text { puntajes más altos en } \\
\text { síntomas de malestar } \\
\text { emocional y menores niveles } \\
\text { de autoeficacia. }\end{array}$ & II-3 \\
\hline 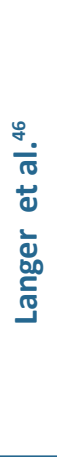 & $\begin{array}{l}\text { Diseño } \\
\text { experimental } \\
\text { con grupos } \\
\text { aleatorizados } \\
\text { por un método } \\
\text { estratificado por } \\
\text { género. }\end{array}$ & $\begin{array}{l}\text { Se excluyeron CPI } \\
\text { con presencia } \\
\text { o historia de } \\
\text { algún trastorno } \\
\text { neurológico. } \\
\text { Los participantes } \\
\text { se asignaron a } \\
\text { los grupos } \\
\text { aproximadamente } \\
\text { al día } 50 \text { post- } \\
\text { TCPH. }\end{array}$ & $\begin{array}{l}\text { Se emplearon pruebas de } t \\
\text { de Student y Chi cuadrada } \\
\text { para evaluar las características } \\
\text { sociodemográficas preTCPH con } \\
\text { base en el grupo de pertenencia. } \\
\text { Se emplearon métodos de } \\
\text { ecuaciones de estimación } \\
\text { generalizada para modelar las } \\
\text { mediciones repetidas de las } \\
\text { evaluaciones subjetivas, las } \\
\text { expresiones y los indicadores } \\
\text { fisiológicos entre y dentro de las } \\
\text { sesiones. }\end{array}$ & $\begin{array}{l}44 \text { pacientes rechazaron } \\
\text { participar en el estudio. De } \\
122 \text { incorporados preTCPH, } \\
34 \text { perdieron seguimiento. Se } \\
\text { aleatorizaron sólo } 88 \mathrm{CPI} \text { y } \\
30 \text { fueron incluidos en otro } \\
\text { estudio piloto. } \\
\text { De los } 29 \mathrm{CPI} \text { del grupo } \\
\text { de intervención uno no } \\
\text { completó ninguna sesión y } \\
\text { dos sólo acudieron a una } \\
\text { sesión. }\end{array}$ & 1 \\
\hline 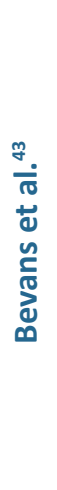 & $\begin{array}{l}\text { Diseño de } \\
\text { grupo único } \\
\text { con muestras } \\
\text { repetidas y } \\
\text { métodos mixtos. }\end{array}$ & $\begin{array}{l}\text { Todas las diadas } \\
\text { estuvieron } \\
\text { compuestas por } \\
\text { el paciente y su } \\
\text { esposo(a). } \\
\text { El } 87 \% \text { de las } \\
\text { diadas eran de } \\
\text { etnia no hispana, } \\
\text { caucásicos. }\end{array}$ & $\begin{array}{l}\text { La transcripción de las entrevistas } \\
\text { se analizó descriptivamente y } \\
\text { se identificaron e hicieron } \\
\text { referencias cruzadas por } \\
\text { temáticas. El tamaño del efecto se } \\
\text { determinó de los puntajes de la } \\
\text { línea base a la última evaluación } \\
\text { de seguimiento. } \\
\text { Mediante la correlación de } \\
\text { Spearman se exploró la relación } \\
\text { entre el malestar emocional, } \\
\text { funcionamiento basal y cambio } \\
\text { con las habilidades de solución de } \\
\text { problemas. }\end{array}$ & $\begin{array}{l}\text { Falta de grupo control. } \\
\text { Se habían contemplado } 34 \\
\text { diadas, de las cuales } 24 \text { no } \\
\text { fueron posibles de incluir por } \\
\text { diversos motivos. } \\
\text { De las } 10 \text { diadas, dos fueron } \\
\text { eliminadas por muerte del } \\
\text { paciente (1) y respuestas } \\
\text { inconsistentes (1). }\end{array}$ & II-3 \\
\hline
\end{tabular}




\begin{tabular}{|c|c|c|c|c|c|}
\hline 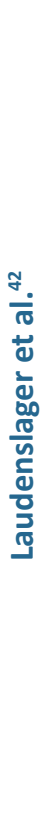 & $\begin{array}{l}\text { Diseño } \\
\text { experimental pre } \\
\text { post. } \\
\text { Se garantizó una } \\
\text { confiabilidad } \\
\text { (>90\%) verificada } \\
\text { con la revisión } \\
\text { aleatorizada de } \\
\text { los vídeos del } 20 \% \\
\text { de las sesiones. }\end{array}$ & $\begin{array}{l}\text { Se excluyeron CPI } \\
\text { con antecedentes } \\
\text { de algún trastorno } \\
\text { psiquiátrico en los } \\
\text { últimos } 18 \text { meses } \\
\text { o enfermedad } \\
\text { médica que } \\
\text { pudiera } \\
\text { afectar los } \\
\text { biomarcadores. }\end{array}$ & $\begin{array}{l}\text { Se emplearon análisis descriptivos } \\
\text { para asegurar similitudes entre } \\
\text { los grupos PEPRR y TAU. } \\
\text { Los valores normalizados de } \\
\text { la expresión genética fueron } \\
\text { transformados en log2 para un } \\
\text { análisis factorial lineal Grupo X } \\
\text { Tiempo. Los genes con respuesta } \\
\text { diferenciada fueron identificados } \\
\text { como aquellos con una } \\
\text { interacción Grupo X Tiempo > } 1.5 \\
\text { veces su magnitud. } \\
\text { Los análisis primarios usaron } \\
\text { análisis de bioinformática TELiS } \\
\text { para medir los elementos de } \\
\text { respuesta pro-inflamatoria de } \\
\text { genes que muestran down- } \\
\text { regulation a través del tiempo. }\end{array}$ & $\begin{array}{l}\text { Inicialmente se incluyeron } \\
149 \text { sujetos de un estudio } \\
\text { de padres; de ellos se } \\
\text { excluyeron } 104 \text { por no tener } \\
\text { muestras disponibles. Se } \\
\text { aleatorizaron } 45 \text { sujetos; de } \\
\text { los cuales } 23 \text { se asignaron } \\
\text { al grupo PEPRR y } 22 \text { a } \\
\text { TAU. Del grupo PEPRR, dos } \\
\text { participantes no recibieron la } \\
\text { intervención; a los tres meses } \\
\text { dos perdieron seguimiento y } \\
\text { cinco fueron eliminados del } \\
\text { estudio; por lo que fueron } \\
\text { analizados } 13 \text { sujetos, de los } \\
\text { cuales en uno la muestra de } \\
\text { células fue inadecuada y en } \\
\text { dos se perdieron las muestras } \\
\text { de sangre. } \\
\text { Para el perfil de expresión } \\
\text { genética sólo se procesaron } \\
\text { las muestras de sangre } \\
\text { previas a la aleatorización y la } \\
\text { de los tres meses posTCPH. }\end{array}$ & I \\
\hline 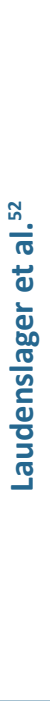 & $\begin{array}{l}\text { Estudio } \\
\text { controlado } \\
\text { aleatorizado 1:1 } \\
\text { con análisis por } \\
\text { intención de } \\
\text { tratamiento. } \\
\text { Las diadas } \\
\text { recibieron una } \\
\text { remuneración } \\
\text { económica por su } \\
\text { participación en } \\
\text { el estudio. }\end{array}$ & $\begin{array}{l}\text { Se incluyeron } \\
\text { todos los } \\
\text { pacientes } \\
\text { sometidos a TCPH } \\
\text { alogénico y } \\
\text { su cuidador } \\
\text { primario. } \\
\text { Se excluyeron CPI } \\
\text { o pacientes con } \\
\text { algún trastorno } \\
\text { psiquiátrico } \\
\text { descontrolado no } \\
\text { relacionado con } \\
\text { la enfermedad del } \\
\text { paciente en los } \\
\text { últimos } 18 \text { meses. } \\
\text { Además de CPI } \\
\text { que consumieran } \\
\text { más de } 2 \text { copas de } \\
\text { alcohol por día. }\end{array}$ & $\begin{array}{l}\text { Todos los análisis de comparación } \\
\text { emplearon niveles de significancia } \\
0.05 \text { de dos colas. } \\
\text { Se analizaron de manera } \\
\text { separada las variables primarias y } \\
\text { secundarias de los CPI mediante } \\
\text { múltiples modelos de covarianza } \\
\text { a partir de los efectos de } \\
\text { intervención, meses, lugar y su } \\
\text { interacción y efecto aleatorizado } \\
\text { del participante. } \\
\text { El tamaño de la muestra de } 155 \\
\text { pares de pacientes / CPI provee } \\
\text { entre } 80 \% \text { a } 95 \% \text { de poder de } \\
\text { detección de tamaño del efecto } \\
\text { en un rango de } 0.23 \text { a } 0.30 \text {. }\end{array}$ & $\begin{array}{l}\text { Debido a los criterios } \\
\text { de inelegibilidad no se } \\
\text { incluyeron } 179 \text { diadas (más } \\
\text { de las diadas incluidas). } \\
\text { Además de los CPI que } \\
\text { rechazaron participar } \\
\text { principalmente al indicar que } \\
\text { estaban muy ocupados por el } \\
\text { cuidado del paciente. } \\
\text { El FACT-BMT y el CG-distress } \\
\text { no mostraron buena validez } \\
\text { en las mediciones esperadas. } \\
\text { No se recopiló información } \\
\text { sobre la relación entre el } \\
\text { paciente y el cuidador. }\end{array}$ & 1 \\
\hline 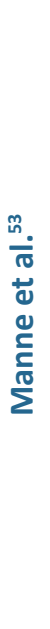 & $\begin{array}{l}\text { Estudio clínico } \\
\text { aleatorizado por } \\
\text { estratificación } \\
\text { según género y } \\
\text { lenguaje. } \\
\text { Los CPI recibieron } \\
\text { una remuneración } \\
\text { económica por su } \\
\text { participación. }\end{array}$ & $\begin{array}{l}\text { CPI de pacientes } \\
\text { pediátricos } \\
\text { provenientes de } \\
\text { cuatro centros de } \\
\text { TCPH de Estados } \\
\text { Unidos. } \\
\text { Se excluyó a CPI } \\
\text { de pacientes con } \\
\text { diagnóstico de } \\
\text { cáncer cerebral. }\end{array}$ & $\begin{array}{l}\text { Se realizó un modelamiento } \\
\text { multinivel para examinar } \\
\text { diferencias significativas entre los } \\
\text { grupos a través del tiempo en el } \\
\text { que se codificaron tres efectos. } \\
\text { Este análisis arrojó un efecto } \\
\text { por el tratamiento, efecto por } \\
\text { el tiempo y por la interacción } \\
\text { tratamiento - tiempo. } \\
\text { Para evaluar el efecto de } \\
\text { moderadores continuos o } \\
\text { dicotómicos se simplificó el } \\
\text { análisis usando un modelamiento } \\
\text { multinivel mediante regresión } \\
\text { en el cual la condición fue la } \\
\text { codificación del efecto y el tiempo } \\
\text { fue tratado como una variable } \\
\text { cuantitativa. }\end{array}$ & $\begin{array}{l}\text { Fue un estudio abierto para } \\
\text { todos los involucrados en el } \\
\text { estudio. } \\
\text { Gran parte de los } \\
\text { participantes del grupo de } \\
\text { intervención no completaron } \\
\text { las entrevistas de } \\
\text { seguimiento en comparación } \\
\text { con el grupo control. } \\
\text { El abandono de tratamiento } \\
\text { en el grupo de intervención } \\
\text { puede ser un sesgo en } \\
\text { los resultados y potencial } \\
\text { impacto benéfico de la } \\
\text { intervención. }\end{array}$ & I \\
\hline
\end{tabular}




\begin{tabular}{|c|c|c|c|c|c|}
\hline 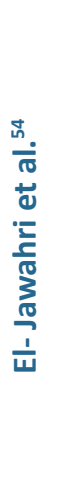 & $\begin{array}{l}\text { Estudio clínico } \\
\text { aleatorizado no } \\
\text { ciego de una } \\
\text { intervención } \\
\text { psicosocial } \\
\text { multimodal versus } \\
\text { el tratamiento } \\
\text { usual. }\end{array}$ & $\begin{array}{l}\text { Si el paciente } \\
\text { no tenía CPI al } \\
\text { momento del } \\
\text { TCPH, se le pedía } \\
\text { autorización } \\
\text { para contactar } \\
\text { a su CPI quien } \\
\text { podía aceptar } \\
\text { participar durante } \\
\text { la llamada } \\
\text { telefónica. } \\
\text { El 93\% de los } \\
\text { participantes eran } \\
\text { caucásicos. }\end{array}$ & $\begin{array}{l}\text { Se emplearon análisis de } \\
\text { covarianza controlando los } \\
\text { puntajes de línea base para } \\
\text { examinar los efectos del BMT- } \\
\text { CARE sobre la calidad de vida, } \\
\text { carga del cuidador, depresión, } \\
\text { ansiedad, autoeficacia y } \\
\text { habilidades de afrontamiento. } \\
\text { Se usó un modelo mixto de efecto } \\
\text { lineal con máxima verosimilitud } \\
\text { para examinar los cambios a } \\
\text { través del tiempo. }\end{array}$ & $\begin{array}{l}\text { Estudio monocéntrico } \\
\text { con reducida diversidad } \\
\text { sociodemográfica, lo que } \\
\text { limita la validez externa. } \\
\text { Al ser un estudio abierto, } \\
\text { puede haber un sesgo. } \\
\text { No se recolectaron datos } \\
\text { a largo plazo para evaluar } \\
\text { el mantenimiento de los } \\
\text { cambios. }\end{array}$ & I \\
\hline 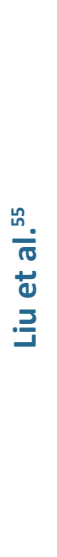 & $\begin{array}{l}\text { Diseño } \\
\text { longitudinal } \\
\text { de muestras } \\
\text { repetidas. } \\
\text { Grupos } \\
\text { aleatorizados. }\end{array}$ & $\begin{array}{l}\text { Se incluyeron } \\
\text { CPI de pacientes } \\
\text { con cualquier } \\
\text { condición } \\
\text { maligna o no que } \\
\text { requiriera un } \\
\text { TCPH alogénico. } \\
\text { Se retiraba del } \\
\text { estudio al CPI } \\
\text { si el paciente } \\
\text { presentaba } \\
\text { recaída, falla } \\
\text { al injerto o era } \\
\text { transferido } \\
\text { a cuidados } \\
\text { intensivos. }\end{array}$ & $\begin{array}{l}\text { Las diferencias en las } \\
\text { características y variables clínicas } \\
\text { entre los grupos en la línea base } \\
\text { fueron evaluadas mediante Chi2 } \\
\text { para variables categóricas y U de } \\
\text { Mann-Whitney para variables } \\
\text { continuas. } \\
\text { Las diferencias entre grupos pero } \\
\text { en diferentes momentos fueron } \\
\text { evaluadas mediante prueba } \\
\text { de Wilcoxon. El efecto de la } \\
\text { intervención a lo largo del tiempo } \\
\text { se evaluó mediante ecuaciones } \\
\text { de estimación generalizadas. }\end{array}$ & $\begin{array}{l}\text { Estudio abierto para los } \\
\text { participantes, lo cual } \\
\text { incrementa el sesgo en las } \\
\text { variables relacionadas con la } \\
\text { intervención. } \\
\text { Existen aspectos que limitan } \\
\text { la generalización de los } \\
\text { resultados como el hecho de } \\
\text { que se condujo en un solo } \\
\text { centro hospitalario y que } \\
\text { al grupo control solo se le } \\
\text { ofrecían limitados servicios } \\
\text { de soporte. }\end{array}$ & I \\
\hline
\end{tabular}

CTFPHC: Equipo de trabajo canadiense sobre la atención médica preventiva ${ }^{40}$; PCS: Puntaje del Componente Físico; MCS: Puntaje del Componente Mental; PEPRR: Programa de psicoeducación, respiración rítmica y relajación; TAU: Programa de tratamiento usual; CPI: Cuidadores Primarios Informales; FACT-BMT: Evaluación Funcional de la Terapia para cáncer- Trasplante de Médula Ósea; CG-distress: Caregiver distress

\section{DISCUSIÓN}

Es importante señalar que la mayoría de estos estudios fueron ensayos clínicos controlados y aleatorizados, los cuales cumplen con criterios metodológicos estrictos en relación a la validez interna ${ }^{4-53}$. Sin embargo, presentan dificultades para la validez externa al tener grupos primordialmente homogéneos que limitan la diversidad demográfica ${ }^{41-52}$. Estas características no permiten la representatividad de otros grupos como la población latina que cuenta con condiciones sociodemográficas, ideológicas y culturales diferentes que podrían causar variación en los hallazgos observados.

Entre las intervenciones que reportaron mayores cambios benéficos $44,46,53,54$, resalta que incluyeron sesiones de mínimo una hora, mismas que se implementaron los días posteriores al trasplante, cuando el paciente se encontraba en atención ambulatoria. Este momento, en términos psicológicos puede ser identificado como clave para mejorar las probabilidades de beneficio del tratamiento psicoterapéutico ${ }^{49}$. El alta de hospitalización del paciente sometido a trasplante se convierte en una etapa en la cual se exige el mayor esfuerzo para los cuidadores, pues deberán asumir las responsabilidades que en la fase de hospitalización fueron cubiertas por los profesionales de la salud. Entre las responsabilidades se describe implementar acciones de limpieza para evitar focos de infección, acondicionar un espacio limpio, seguro y adecuado para el descanso del paciente, administrar correctamente medicamentos, propiciar comportamientos enfocados en la salud, como la preparación de alimentos y apoyo en las medidas de higiene personal ${ }^{6}$. 
Debido a esto, implementar intervenciones psicológicas durante esta transición puede representar, desde la perspectiva de Cohen, un momento clave en la motivación de los cuidadores para fomentar su participación prevenir malestar emocional, desgaste físico y deterioro mental; así como mejorar las posibilidades de éxito del trasplante. Un posible mecanismo de influencia es que mediante la intervención se brindan estrategias de afrontamiento, solución de problemas, entrenamiento en competencias conductuales y regulación emocional con el objetivo de ampliar o reforzar el repertorio conductual del CPI, favoreciendo así cambios de primer orden para una mejor adaptación ${ }^{47}$; en este caso, del cuidador a las demandas que deberá cumplir.

A pesar de lo anterior se observan resultados contradictorios en relación al beneficio mostrado por las intervenciones y el tamaño del efecto; lo cual no demerita la relevancia del desarrollo e implementación de las intervenciones descritas; así como los efectos benéficos observados en la mayoría de ellas.

Por lo anterior, la evidencia mostrada en esta revisión permite enfatizar en la importancia de evaluar y atender oportunamente la salud mental de los CPI de pacientes sometidos a tratamientos como un TCPH; esto con el objetivo de mejorar la calidad de atención, además de promover la adaptación del enfermo y su cuidador a las condiciones requeridas; así mismo, prevenir a largo plazo efectos psicológicos negativos en los CPI.

Sumado a lo anterior, se debe resaltar que, para poblaciones latinoamericanas, los resultados mostrados en las intervenciones descritas son difícilmente aplicables debido a las diferencias sociodemográficas y culturales de nuestra población, además del contexto en el que se enfrentan al no contar con el soporte de países desarrollados como en los que se llevaron a cabo los estudios reportados. En este sentido, en población mexicana es trascendental incluir aspectos como lo es el estrés asociado a las dificultades económicas que enfrentan las familias para garantizar los recursos necesarios para la adquisición de medicamentos y el pago de los servicios médicos; además de considerar que alrededor del 50\% de los pacientes junto con sus cuidadores deben abandonar su ciudad de origen para recibir atención médica.

\section{CONCLUSIÓN}

Referente al objetivo, se logró evidenciar que las intervenciones estudiadas muestran mejoras en diferentes variables psicológicas de los CPI, sin embargo, no se logra consistencia en demostrar que estos avances sean estadísticamente significativos y con cambios clínicos de por lo menos moderada fuerza.

A pesar de ello consideramos que el presente estudio brinda solidez a la importancia de continuar con la investigación e implementación de intervenciones psicológicas en los CPI de pacientes sometidos a tratamientos demandantes o invasivos; orientadas a la prevención de trastornos de salud mental en el cuidador, y el progresivo efecto benéfico en el receptor de trasplante.

Como parte de lo observado a lo largo de la revisión de literatura recomendamos la implementación de evaluaciones e intervenciones sistematizadas en CPI de este grupo de pacientes; las cuales podrían ser útiles para disminuir la prevalencia de alteraciones crónicas, psicológicas, emocionales y físicas en los cuidadores.

Es primordial fomentar la sensibilidad hacia el cuidado de la salud mental de los cuidadores como parte de tratamiento integral para el paciente, el cuidado de su contexto y red de apoyo para mejorar las posibilidades de éxito de los tratamientos, así como potencializar los probables beneficios. En 
este sentido la revisión permite a los profesionales en salud mental, identificar las estrategias que han mostrado mejores resultados.

Dichas situaciones, así como la saturación de los servicios de salud pública en México, los limitados recursos personales y la deficiente infraestructura para la atención de salud mental y general del CPI, pueden representar importantes obstáculos para la implementación de intervenciones en nuestro contexto. Sin embargo, también permiten vislumbrar líneas de investigación con aristas sobre el estudio de las estrategias ya probadas que pudieran adaptarse a situaciones a través de mecanismos con un menor requisito de respuesta, llevarse a cabo en días previos al egreso del paciente cuando hay menor carga para el cuidador y efectuarlas en horarios cercanos a la visita de su familiar, entre otras.

Estas consideraciones, más las derivadas del propio estudio de las características de la población mexicana, pueden conducir al desarrollo de estrategias con fines prácticos como el entrenamiento en solución de problemas cotidianos, habilidades de comunicación y búsqueda de apoyo social; las cuales facilitan herramientas a los CPI para afrontar las demandas a las que son expuestos en su quehacer como cuidadores, pero también en la vida cotidiana.

Para concluir, es recomendable mejorar la validez interna y externa de las intervenciones para que los beneficios de éstas sean tangibles en la atención tanto del paciente como de sus CPI conllevando a un menor riesgo de complicaciones y comorbilidades en salud.

\section{RESPONSABILIDADES ÉTICAS}

Protección de personas y animales. Al ser un estudio de revisión no se realizaron experimentos ni intervenciones.

Confidencialidad. Al ser un estudio, no se tuvo contacto con participantes.

Conflicto de intereses. Los autores declaran no tener conflicto de intereses.

Financiamiento. Ninguno.

\section{REFERENCIAS}

1. Health Resources and Services Administration HRSA, Blood Stem Cell. EE. UU.: Transplant Activity Report; c2O2O. https://bit.ly/3dPDt4H

2. Kaushasky K, Lichtman MA, Prchal JT, Levi MM, Press OW, Burns LJ, et al. Williams Hematology. $9^{\text {th }}$ ed. EE. UU.: McGraw-Hill; 2016.

3. World Health Organization. Geneva, Switzerland: Haematopoietic Stem Cell Transplantation HSCtx; c2020. https://bit.ly/31sRbW7

4. Territo MC, Casciato DA. Manual de Oncología Clínica. $7^{\text {th }}$ ed. Pensilvania, EUA: Wolters Kluwer/ Lippincott Williams y Wilkins; 2013.

5. $\quad$ National Cancer Institute. EE.UU.: Stem cell transplants in cancer treatment; 2015. https://bit.ly/3jhxKW9

6. Applebaum AJ, Bevans M, Son T, Evans K, Hernandez M, Giralt S, et al. A scoping review of caregiver burden during allogeneic HSCT: Lessons learned and future directions. Bone Marrow Transplant. 2016; 51(11): 1416-22. https://doi.org/10.1038/bmt.2016.164

7. Díaz-Rubio E, García-Conde J. Oncología Clínica Básica. España: Arán Ediciones; 2000.

8. Majhail NS, Rizzo JD, Hahn T, Lee SJ, McCarthy PL, Ammi M, et al. Pilot study of patient and caregiver out-of-pocket costs of allogeneic hematopoietic cell transplantation. Bone Marrow Transplant. 2013; 48(6): 865-71. https://doi.org/10.1038/bmt.2012.248 
9. Aslan O, Kav S, Meral C, Tekin F, Yesil H, Ozturk U, et al. Needs of lay caregivers of bone marrow transplant patients in Turkey: A multicenter study. Cancer Nurs. 2006; 29(6): E1-7.

https://doi.org/10.1097/00002820-200611000-00014

10. Beattie S, Lebel S.The experience of caregivers of hematological cancer patients undergoing a hematopoietic stem cell transplant: a comprehensive literature review. Psychooncology. 2011; 20(11): 1137-5o. http://doi.org/10.1002/pon.1962

11. Rivera-Fong L, Landa-Ramírez E, Valero-Saldaña LM, Riveros-Rosas A. Efectos de una intervención cognitivo conductual y actividad física sobre variables médicas y psicológicas en pacientes sometidos a trasplante hematopoyético de células madre. Psicooncología. 2014; 11(2-3): 217-31.

https://doi.org/10.5209/rev_PSIC.2014.v11.n2-3.47384

12. Bevans M, Wehrlen L, Prachenko O, Soeken K, Zabora J, Wallen GR. Distress screening in allogeneic hematopoietic stem cell (HSCT) caregivers and patients. Psychooncology. 2011; 20(6): 615-22. https://doi.org/10.1002/pon.1906

13. Hoffman LH, Szkrumelak N, Sullivan AK. Psychiatric assessment of candidates for bone marrow transplantation: a psychodynamically-oriented approach. Int J Psychiatry Med. 1999; 29(1):13-28. https://doi.org/10.2190/1c24-h366-cgc9-v1pw

14. Rodrigue JR, Windows MR, Baz MA. Caregivers of lung transplant candidates: Do they benefit when the patient is receiving psychological services? Prog Trasnplant. 2006; 16(4): 336-42.

https://bit.ly/36NtH1m

15. Ross A, Yang L, Klagholz SD, Wehrlen L, Bevans MF. The relationship of health behaviors with sleep and fatigue in transplant caregivers. Psychooncology. 2016; 25(5): 506-12.

https://doi.org/10.1002/pon.3860

16. Simoneau TL, Kilbourn K, Spradley J, Laudenslager ML. An evidence-based stress management intervention for allogeneic hematopoietic stem cell transplant caregivers: Development, feasibility and acceptability. Support Care Cancer. 2017; 25(8): 2515-23

https://doi.org/10.1007/s00520-017-3660-5

17. Wei L, Li J, Cao Y, Xu J, Qin W, Lu H. Quiality of life and care burden in primary caregivers of liver transplantation recipients in China. Medicine. 2018; 97(24): e10993.

https://doi.org/10.1097/MD.0000000000010993

18. Foster LW, McLellan L, Rybicki L, Dabney J, Copelan E, Bolwell B. Validating the positive impact of in-hospital lay care-partner support on patient survival in allogeneic BMT: A prospective study. Bone Marrow Transplant. 2013; 48(5): 671-7. https://doi.org/10.1038/bmt.2012.208

19. Gemmill R, Cooke L, Williams AC, Grant M. Informal caregivers of hematopoietic cell transplant patients: a review and recommendations for interventions and research. Cancer Nurs. 2011; 34(6): E13-21. https://doi.org/10.1097/NCC.obo13e31820a592d

20. Sundaramurthi T, Wehrlen L, Friedman E, Thomas S, Bevans M. Hematopoietic stem cell transplantation recipient and caregiver factors affecting length of stay and readmission. Oncol Nurs Forum. 2017; 44(5): 571-9. https://doi.org/10.1188/17.onf.571-579

21. Beattie S, Lebel S, Tay J. The influence of social support on hematopoietic stem cell transplantation survival: A systematic review of literature. PLoS One. 2013; 8(4): 1-6.

https://doi.org/10.1371/journal.pone.0061586

22. Rodrigue JR, Pearman TP, Moreb J. Morbidity and mortality following bone marrow transplantation: predictive utility of pre-BMT affective functioning, compliance, and social support stability. Int J Behav Med. 1999; 6(3): 241-54. https://doi.org/10.1207/s15327558ijbmo603_3 
23. Posluszny DM, Bovbjerg DH, Agha ME, Hou JZ, Raptis A, Boyiadzis MM, et al. Patient and family caregiver dyadic adherence to the allogeneic hematopoietic cell transplantation medical regimen. Psychooncology. 2017; 27(1): 354-8. https://doi.org/10.1002/pon.4393

24. Wulff-Burchfield EM, Jagasia M, Savani BN. Long-term follow-up of informal caregivers after alloSCT: A systematic review. Bone Marrow Transplant. 2013; 48(4): 469-73.

https://doi.org/10.1038/bmt.2012.123

25. Blum K, Sherman DW. Understanding the experience of caregivers: A focus on transitions. Semin Oncol Nurs. 2010; 26(4): 243-58. https://doi.org/10.1016/j.soncn.2010.08.005

26. Northouse L, Williams AL, Given B, McCorkle R. Psychosocial care for family caregivers of patients with cancer. J Clin Oncol. 2012; 30(11): 1227-34. https://doi.org/10.1200/JCO.2011.39.5798

27. Gerhart JI, Asvat Y, Lilis TA, Fung H, Grosse J, Hobfoll SE. The impact of posttraumatic stress symptoms on social support and social conflict during hematopoietic stem cell transplant. J Psychosoc Oncol. 2018; 36(3): 304-18. https://doi.org/10.1080/07347332.2018.1425793

28. Langer SL, Yi JC, Storer BE, Syrjala KL. Marital adjustment, satisfaction and dissolution among hematopoietic stem cell transplant patients and spouses: A prospective, five-year longitudinal investigation. Psychooncology. 2010; 19(2): 190-200. https://doi.org/10.1002/pon.1542

29. Simoneau TL, Mikulich-Gilbertson SK, Natvig C, Kilbourn K, Spradley J, Grzywa-Cobb R, et al. Elevated peri-transplant distress in caregivers of allogeneic blood or marrow transplant patients. Psychooncology. 2013; 22(9): 2064-70. https://doi.org/10.1002/pon.3259

30. Bishop MM, Beaumont JL, Hahn EA, Cella D, Andrykowski MA, Brady MJ, et al. Late effects of cancer and hematopoietic stem-cell transplantation on spouses or partners compared with survivors and survivor-matched controls. J Clin Oncol. 2007; 25(11): 1403-11.

https://doi.org/10.1200/JCO.2006.07.5705

31. Bevans MF, Ross A, Wehrlen L, Klagholz SD, Yang L, Childs R, et al. Documenting stress in caregivers of transplantation patients: Initial evidence of HPA dysregulation. Stress. 2016; 19(2): 175-84 https://doi.org/10.3109/10253890.2016.1146670

32. Foxall MJ, Gaston-Johansson F. Burden and health outcomes of family caregivers of hospitalized bone marrow transplant patients. J Adv Nurs. 1996; 24(5): 915-23.

https://doi.org/10.1111/j.1365-2648.1996.tbo2926.x

33. Gaston-Johansson F, Lachica EM, Fall-Dickson JM, Kennedy MJ. Psychological distress, fatigue, burden of care, and quality of life in primary caregivers of patients with breast cancer undergoing autologous bone marrow transplantation. Oncol Nurs Forum. 2004; 31(6): 1161-9.

https://doi.org/10.1188/04.onf.1161-1169

34. Given B, Wyatt G, Given C, Sherwood P, Gift A, DeVoss D, et al. Burden and depression among caregivers of patients with cancer at the end of life. Oncol Nurs Forum. 2004; 31(6): 1105-17. https://doi.org/10.1188/04.ONF.1105-1117

35. Son T, Lambert S, Jakubowski A, DiCicco-Bloom B, Loiselle CG. Adaptation of coping together - a self-directed coping skills intervention for patients and caregivers in an outpatient hematopoietic stem cell transplantation setting: a study protocol. BMC Health Serv Res. 2018; 18(1): 669. https://doi.org/10.1186/s12913-018-3483-1

36. Vinci C, Reblin M, Jim H, Pidala J, Bulls H, Cutolo E. Understanding preferences for a mindfulnessbased stress management program among caregivers of hematopoietic cell transplant patients. Complement Ther Clin Pract. 2018; 33: 164-9. https://doi.org/10.1016/j.ctcp.2018.10.007 
37. Beattie S, Lebel S, Petricone-Westwood D, Wilson KG, Harris C, Devins G, et al. Balancing give and take between patients and their spousal caregivers in hematopoietic stem cell transplantation. Psychooncology. 2017; 26(12): 2224-31. https://doi.org/10.1002/pon.4340

38. Manne S, Mee L, Bartell A, Sands S, Kashy DA. A randomized clinical trial of a parent-focused socialcognitive processing intervention for caregivers of children undergoing hematopoetic stem cell transplantation. J Consult Clin Psychol. 2016; 84(5): 389-401.

https://doi.org/10.1037/ccpoo00087

39. Sands SA, Mee L, Bartell A, Manne S, Devine KA, Savone M, et al. Group-Based trajectory modeling of distress and well-being among caregivers of children undergoing hematopoetic stem cell transplant. J Pediatr Psychol. 2017; 42(3): 283-95. https://doi.org/10.1093/jpepsy/jswo64

40. Manterola DC, Zavando MD. Cómo interpretar los "Niveles de Evidencia" en los diferentes escenarios clínicos. Rev Chil Cir. 2009; 61(6): 582-95. http://dx.doi.org/10.4067/So718-40262009000600017

41. Laudenslager ML, Simoneau TL, Kilbourn K, Natvig C, Philips S, Spradley J, et al. A randomized control trial of a psychosocial intervention for caregivers of allogeneic hematopoietic stem cell transplant patients: Effects on distress. Bone Marrow Transplant. 2015; 50(8): 1110-18.

https://doi.org/10.1038/bmt.2015.104

42. Laudenslager ML, Simoneau TL, Philips S, Benitez P, Natvig C, Cole S. A randomized controlled pilot study of inflammatory gene expression in response to a stress management intervention for stem cell transplant caregivers. J Behav Med. 2016; 39(2): 346-54.

https://doi.org/10.1007/s10865-015-9709-3

43. Bevans M, Castro K, Prince P, Shelburne N, Prachenko O, Loscalzo M, et al. An individualized dyadic problem-solving education intervention for patients and family caregivers during allogeneic hematopoietic stem cell transplantation: a feasibility study. Cancer Nurs. 2010; 33(2): E24-32 https://doi.org/10.1097/NCC.obo13e3181be5e6d

44. Bevans M, Wehrlen L, Castro K, Prince P, Shelburne N, Soeken K, et al. A problem-solving education intervention in caregivers and patients during allogeneic hematopoietic stem cell transplantation. J Health Psychol. 2014; 19(5): 602-17 https://doi.org/10.1177/1359105313475902

45. Stonnington CM, Darby B, Santucci A, Mulligan P, Pathuis P, Cuc A, et al. A resilience intervention involving mindfulness training for transplant patients and their caregivers. Clin Transplant. 2016; 30(11): 1466-72. https://doi.org/10.1111/ctr.12841

46. Langer SL, Kelly TH, Storer BE, Hall SP, Lucas HG, Syrjala KL. Expressive talking among caregivers of hematopoietic stem cell transplant survivors: Acceptability and concurrent subjective, objective, and physiologic indicators of emotion. J Psychos Oncol. 2012; 30(3): 294-315

https://doi.org/10.1080/07347332.2012.664255

47. Cormier S, Nurius SP, Osborn CJ. Interviewing and change strategies for helpers. $8^{\text {th }}$ ed. EE.UU.: Cengage Learning; 2016.

48. Caqueo-Urízar A, Alessandrini M, Urzúa A, Zendjidjian X, Boyer L, Williams DR. Caregiver's quality of life and its positive impact on symptomatology and quality of life of patients with schizophrenia. Health Oual Life Outcomes. 2017; 15: 76. https://doi.org/10.1186/s12955-017-0652-6

49. Ready RE, Mathews M, Leserman A, Paulsen IS. Patients and caregiver quality of life in Huntington's disease. Mov Disord. 2008; 23(5): 721-6. https://doi.org/10.1002/mds.21920

50. Cohen GL, Garcia J, Goyer JP. Turning point: Targeted, tailored, and timely psychological intervention. In Elliot AJ, Dweck CS, Yeager DS, editors. Handbook of competence and motivation: Theory and application New York. EE.UU.: The Guilford Press; 2017. p. 657-86. https://bit.ly/31MSj7d 
51. Ambriz-López MC, Villalobos-Arámbula LM, Gallegos-Torres RM, Xeque-Morales AS, HernándezCastañón MA, Palomé-Vega G. Perfil del cuidador principal y su relación con el cuidado del personal de enfermería. Rev. Enfer. Inst. Mex. Seguro Soc. 2014; 22(3): 123-9. https://bit.ly/zmuqLLK

52. Laudenslager ML, Simoneau TL, Mikulich-Gilberston SK, Natvig C, Brewr BW, Sannes TS, et al. A randomized control trial of stress management for caregivers of stem cell transplant patients: Effect on patient quality of life and caregiver distress. Psycho-Oncology. 2019; 28: 1614-23.

https://doi.org/10.1002/pon.5126

53. Manne S, Mee L, Bartell A, Sands S, Kashy DA. A randomized clinical trial of a parent-focused socialcognitive processing intervention for caregivers of children undergoing hematopoietic stem cell transplantation. J Consult Clin Psychol. 2016; 84(5): 389-401.

https://doi.apa.org/doi/10.1037/ccpooooo87

54. El-Jawahri A, Jacobs JM, Nelson AM, Traeger L, Greer JA, Nicholson S, et al. Multimodal psychosocial intervention for family caregivers of patients undergoing hematopoietic stem cell transplantation: A randomized clinical trial. Cancer. 2020; 0: 1-8. https://doi.org/10.1002/cncr.32680

55. Liu YM, Wen YC, Weng PY, Jaing TH, Chen SH. Exploring the concerns and experiences of parents of children scheduled to receive haematopoietic stem cell transplant. J. Adv. Nurs. 2020; 76(7).

https://doi.org/10.1111/jan.14386 